\title{
Religion and depression: a review of the literature
}

\author{
Michael E McCullough and David B Larson \\ National Institute for Healthcare Research, Rockville, MD, USA
}

\begin{abstract}
We reviewed data from approximately 80 published and unpublished studies that examined the association of religious affiliation or involvement with depressive symptoms or depressive disorder. In these studies, religion was measured as religious affiliation; general religious involvement; organizational religious involvement; prayer or private religious involvement; religious salience and motivation; or religious beliefs. People from some religious affiliations appear to have an el evated risk for depressive symptoms and depressive disorder, and people with no religious affiliation are at an elevated risk in comparison with people who are religiously affiliated. People with high levels of general religious involvement, organizational religious involvement, religious salience, and intrinsic religious motivation are at reduced risk for depressive symptoms and depressive disorders. Private religious activity and particular religious beliefs appear to bear no reliable relationship with depression. People with high level s of extrinsic religious motivation are at increased risk for depressive symptoms. Although these associations tend to be consistent, they are modest and are substantially reduced in multivariate research. Longitudinal research is sparse, but suggests that some forms of religious involvement might exert a protective effect against the incidence and per sistence of depressive symptoms or disorders. The existing research is sufficient to encourage further investigation of the associations of religion with depressive symptoms and disorder. Religion should be measured with higher methodological standards than those that have been accepted in survey research to date.
\end{abstract}

Keywords: religion, religious involvement, psychiatric epidemiology, depression, depressive disorder, affective distress, measurement, psychometrics

Depression is one of the most common mental disorders. Within their lifetime, between 10 and $25 \%$ of women and $5-12 \%$ of men will meet the criteria for major depressive disorder, while at any given point in time between 5 and $12 \%$ of women and $2-3 \%$ of men meet the criteria for major depressive disorder. ${ }^{1}$

Depression is expensive financially and in terms of human life. It appears that medical care for depression is on the rise. Pincus et $\mathrm{al}^{2}$ review evidence indicating that visits to physicians for depression increased from 11 million in 1985 to 20.4 million in 1993-1994, and visits that included treatment with an antidepressant medication increased from $5.3 \mathrm{million}$ to $12.4 \mathrm{million}$ in the same time frame. In addition, people with major depression have a substantially increased risk for use of hospital and medical services, suicide attempts, and early death. ${ }^{3}$

Religion is a variable that is not commonly discussed in standard epidemiological conceptualizations of depression. This is not terribly surprising given the traditional difficulty of quantifying religious phenomena, and admittedly, the uncertain epidemiological value of such information today.

Correspondence: Michael E. McCullough, National Institute for Heal thcare Research, 6110 Executive Blvd., Suite 908, Rockville, MD, 20850, USA. Electronic Mail: Mike@nihr.org

Received 11 January 1999; accepted 17 March 1999
Nevertheless, clinical observations and structured investigations since at least Kraeplin ${ }^{4}$ have suggested that depression coincides with various aspects of religion. The cumulative weight of 100 years of structured and unstructured appraisals of the religion-depression relationship has yet to be fully summarized and reviewed.

In the present paper, we try to accomplish this task. Our discussion is divided into three sections. First, we review the existing research on the prevalence of depression and depressive symptoms among people of various religious affiliations (eg Jews, Catholics, Protestants, and Pentecostals). Second, we examine the research on the relationship between ordinal and interval-level measurements of religious involvement (including measures of organizational religious involvement, religious salience and motivations, private religious activity, and specific religious beliefs). Third, we summarize what these findings might imply for the future study of religion in psychiatric epidemiology.

\section{Religious affiliation and depression}

For a century there have been epidemiological observations that members of some religious groups appear to be at elevated risk for certain mental 
disorders. ${ }^{5}$ In such studies - at least those conducted in the United States - the incidence or preval ence of depression and depressive symptoms among members of particular religious groups are typically compared with those of the general population. Because the US population is approximately $60 \%$ Protestant and $26 \%$ Catholic, ${ }^{6}$ Christian populations usually become a sort of de facto comparison group in such epidemiological studies (at least those conducted in the US). The religious constitution of the hidden comparison group will differ in culture to culture. In cultures where the general population is mostly Muslim, or Hindu, or Buddhist, the conclusions that we draw here probably would not apply.

\section{Jews}

In the United States, Jews represent approximately $2-3 \%$ of the population. ${ }^{6}$ Studies since the 1880 s from across the world have suggested that Jews have an elevated risk for depressive disorders. ${ }^{7}$ Sanua $^{5}$ reviewed a large group of epidemiological and clinical studies related to the prevalence of mental disorders - including depression - among Jews and concluded, citing a variety of cross-sectional studies, ${ }^{8-11}$ that people of Jewish descent appear to be at an el evated risk of depressive disorders. Even when examining the psychiatric symptoms of admissions to psychiatric hospitals, Jews tend to have higher rates of depressive disorders than do non-Jewish admissions. ${ }^{9,12,13}$ As Levav et al ${ }^{7}$ point out, however, most of these studies use clinical populations, and thus might be subject to a variety of biases that could cast doubt on the validity of such findings.

However, more recent studies using community samples and more rigorous research methods also corroborate this general conclusion. In high-quality, community-based epidemiological studies, Jews appear to have approximately a twofold risk for major depression in comparison with members of other religious groups., ${ }^{8,14}$ Using DSM-III diagnoses of major depression as a measure of depression, Levav et al $^{7}$ found the lifetime and period prevalence of major depression to be 1.5 to 2 times that of non-Jews (especially Catholics and Protestants) in two large, random regional samples, even after controlling for relevant covariates.

Is the association of Jewishness and depression causal? Longitudinal studies disagree. One prospective study ${ }^{14}$ followed 1855 older community dwelling adults in the Bronx for 24 months. Kennedy et al found that over a 24-month period, Jews were nearly 1.4 times as likely as Catholics and over 4 times as likely as people from other faiths to develop high scores on the Center For Epidemiological Studies Depression (CES-D) scale. A mong the adults who were not depressed at baseline but became depressed by the 24-month follow-up, Jews were significantly over-represented. Being Jewish remained a risk factor even after controlling for six other covariates of depression. In contrast, Idler and $\mathrm{Kasl}^{17}$ found that in a sample of 2812 older adults from New Haven, CT, being Jewish at baseline actually appeared to lead to lower risk of developing depression over a 3-year follow-up period relative to Catholics (even after controlling for baseline levels of depression and a variety of covariates). Among Jews, risk for depression appears to be associated with many of the standard risk factors for depression (including poor subjective and functional health, lack of social support, and gender). In addition, Jews of Eastern European descent appear particularly vulnerable to depression. ${ }^{18}$ It is also important to acknowledge the fact that Jews - especially Jews of Eastern European descent - may be more willing to admit to negative affects, ${ }^{19}$ creating a potential response bias in depression research. El evated prevalence rates of depression in Jews might also be a trade-off for their reduced rates of alcohol abuse and dependence. Levav et $\mathrm{al}^{7}$ compared data on the prevalence of depression and alcohol use/dependence among Jewish and non-Jewish men and women from the Epidemiological Catchment Area Study (using data from the New Haven, CT, and Los Angeles, CA, sites). These researchers found that (a) excess depression among Jews was attributable only to Jewish men (not Jewish women), and (b) lower al cohol use/dependence among Jews was attributable only to Jewish men (not Jewish women). Jewish and non-Jewish women had roughly equal prevalences of both depression and alcohol abuse/ dependence. Further, combined prevalences of both depression and alcohol abuse/dependence together were not significantly different for Jewish men than they were for non-Jewish men. Furthermore, al cohol use among Jewish men was higher in Los Angeles (the less traditional Jewish community) than in New Haven (the more traditional Jewish community). The observed 2:1 female-male ratio of prevalence rates for depression was obtained in the more secular Jewish community of Los Angeles (where alcohol abuse/dependence among Jewish men was fairly high), whereas the female-male ratio of prevalence rates for depression was approximately $1: 1$ in the more conservative Jewish communities of New Haven (where alcohol abuse/dependence among Jewish men was fairly low).

Since more conservative lews tend to avoid the use of alcohol, Jewish men who have a disposition toward psychopathology might be at a significantly higher risk for experiencing depression instead of al cohol abuse or dependence. This might suggest that in the absence of a proclivity for al cohol abuse/ dependence, Jewish men could be substantially 
more likely to 'express' their latent psychopathology through depressive symptoms.

\section{Catholics}

Catholics constitute approximately $26 \%$ of the American population. ${ }^{20}$ Existing studies are quite inconsistent regarding the relationship between Catholicism and depression. Miller et $\mathrm{al}^{20}$ reported the results of a 10-year prospective study of 60 mothers and 151 of their children. At the 10-year followup, the mothers' religious affiliation was determined. Miller et al found that Catholic mothers were at significantly lower risk of being diagnosed with depression at baseline and at follow-up and were significantly less likely than other mothers to have children who were diagnosed with major depressive disorder at baseline and follow-up. In contrast, Ross $^{15}$ examined denominational differences in scores on an 8-item self-report measure of depressive symptoms. Even when controlling for a variety of potential covariates (including several single-item measures of religious involvement, age, gender, race, marital status, education, income, and willingness to express feelings), Ross found that Catholics had slightly higher depression scores than those of Protestants. Sorenson et $\mathrm{al}^{21}$ found higher depression scores among unwed Catholic mothers than among unwed Protestant mothers. Park et $\mathrm{al}^{22}$ found Catholic women to score lower than Protestant women on measures of depression in one study, but found no such differences in another study. ${ }^{23}$ Still other studies using small samples of recently bereaved adults, ${ }^{24}$ nursing home residents, ${ }^{25}$ and undergraduate students ${ }^{26}$ find Catholicism to have no effect on depression scores.

Even in the best studies - those involving large samples drawn regionally or nationally - results are equivocal at best. Levav et al $^{7}$ reported that Catholics from random samples of adults surveyed as part of the Epidemiologic Catchment Area study in New Haven, CT, and Los Angeles, CA, had prevalence rates of depressive disorder that were approximately $50 \%$ of the preval ence rates among Jews. Jones-Webb and Snowden ${ }^{27}$ also found that among the 1947 black adults in their cross-sectional, nationally representative survey, only $11 \%$ of black Catholics scored in the clinical range on the CES-D scale. Rates of depression were substantially higher among black Protestants and blacks of other faiths (whose depression rates ranged from $21 \%$ for Protestants to $43 \%$ for non-Western religions), and the association of Catholicism with lower rates of depression persisted after controlling for seven demographic and geographic variables (including socio-economic status, marital status, age, and sex). Among the 1747 white respondents, however, no denominational differences in the presence of depressive illness were found, with rates of depression ranging from $14 \%$ to $16 \%$ for all faiths.

This rather mixed picture characterization of the relationship between Catholicism and depression is what one would probably expect if there were no reliable relationship between the two variables. Thus, it would appear that if there is any relationship between Catholicism and depression, this association is probably too trivial and elusive to merit any serious expenditure of money, time, and effort.

\section{Pentecostals/Fundamentalists}

Pentecostal constitute approximately $2 \%$ of the US population. ${ }^{6}$ Some evidence suggests that members of Pentecostal faiths are at an el evated risk for major depression. Meador et $\mathrm{al}^{28}$ examined cross-sectional data from 2850 adults in North Carolina who were involved in the Epidemiological Catchment Area (ECA) study. In their ECA sample, Meador et $\mathrm{al}^{28}$ found that members of Pentecostal churches had rates of major depression that were three times higher than those of the non-Pentecostals. These differences in the rates of major depression held after controlling for a variety of covariates, including gender, age, race, socio-economic status, unexpected life events, and social support.

Another cross-sectional study using the same data set $^{29}$ compared the prevalence rates of depression among Pentecostals to the prevalence rates of depression among members of other Christian faiths. The sample was split into 'baby boomers' (those born between 1945 and 1966) and middle-aged and older adults (those born between 1889 and 1944). Compared with members of other conservative denominations or mainline Christian denominations, the 6-month and lifetime risk of depressive disorders for Pentecostal 'baby boomers' was considerably higher than the 6-month and lifetime risk for 'baby boomers' from other conservative denominations or from mainline Christian denominations. These differences in preval ence held even after controlling for sex, race, physical health, and socio-economic status. Pentecostalism was not associated, however, with differential prevalence rates of depression in the older age group.

Koenig et $\mathrm{al}^{29}$ speculated as to whether the association of Pentecostalism with depression among 'baby boomers' was a causal effect, but is is unclear whether (a) Pentecostalism leads to higher rates of depression; (b) Pentecostalism attracts members who are more likely to be depressed; or (c) some 
third variable that was uncontrolled or poorly controlled is responsible for the apparent association of Pentecostal membership with depression. Meador et $\mathrm{al}^{28}$ speculated that Pentecostals might have, like Jews, higher levels of emotional expression. If this were the case, then their differential rates might be explainable, in part, as a response bias (cf Koenig, ${ }^{30}$ who found that Pentecostal affiliation was associated with fewer depressive symptoms among older men in prison).

\section{No affiliation}

A final group of people whose depressive symptoms have been studied in the context of religion is those who claim to have no religious affiliation at all. Currently, approximately $8 \%$ of the US population claim to have no religious affiliation. ${ }^{6}$ People with no religious affiliation at all appear to be at an elevated risk for depressive symptoms compared with people who are affiliated with a religion. In a sample of 841 medically ill men, Koenig et al $^{31}$ examined whether religious affiliation predicted depression after controlling for demographics, medical status, and a measure of religious coping. They found that when relevant covariates were controlled for, men who indicated that they had 'no religious affiliation' had higher scores on the Hamilton depression rating scale (an observer-administered rating scale) than men who identified themselves as moderate Protestants, Catholics, or non-traditional Christians. Interestingly, the men with 'no religious affiliation' did not score differently from men who were affiliated with various religions on a self-report measure of depression (the Geriatric Depression Scale).

The association of religious disaffiliation with higher degrees of depressive symptoms might be particularly strong among African-Americans. In a sample of 537 African-American males, Brown and Gary ${ }^{32}$ explored the association of scores on the CES$D$ to religious affiliation. They found that men who were not affiliated with a religion had depression scores (mean $=16.95$ ) that were on average 0.60 standard deviation units higher than those of men who were affiliated with a religion (mean $=11.76)$. This effect for religious affiliation persisted even after controlling for church attendance, age, income, education, marital status, and employment status. Ellison ${ }^{33}$ al so reported the results of a study involving a random sample of 2956 adults from the North Carolina site of the Epidemiological Catchment Area (ECA) survey. In this sample, depressive symptoms were assessed using the Diagnostic Interview Schedule. Among white respondents, whether one was affiliated with a religion did not predict degree of depressive symptoms. Among black respondents, however, people who were not affiliated with a religion scored, on average, 0.58 standard deviation units higher on the measure of depressive symptoms. This relationship remained significant (although weaker) after controlling for a number of covariates.

Religious affiliation effects in depression: explanations

Aside from the many methodological explanations that could explain the findings on religious affiliation and depression (eg selection biases, response biases, and differential test validity for certain religious or ethnic groups), a large variety of substantive explanations exist as well. These include genetic explanations, sociological explanations, substantive lifestyle differences, differential exposure to life-changing historical events (eg the Holocaust of World War II), substantive differences in religious and spiritual practices (see also Kennedy ${ }^{34}$ ), and trade-offs in the expression of latent predispositions for psychopathology that lead some groups (eg Jews) to have increased rates of depression, but lower rates of other disorders (eg alcohol abuse/dependence). Although all of these explanations are plausible and should be ruled out formally, we review two potential explanations here that deal specifically with aspects of religion per se.

Religious marginalization The first of these explanations is a sociological one, and relates to the effects of religious marginalization on mental heal th. Some researchers have theorized that the elevated risk of depression among Jews - at least in the US might be related to the marginality of Jewish people in the US. Some research evidence supports the hypothesis that religious marginalization - being religiously different from one's cultural surround creates social conditions that foster depression. For example, Rosenberg ${ }^{34}$ conducted a cross-sectional survey with a sample of high school juniors and seniors (495 Catholics, 405 Protestants, and 121 Jews). He found that children reared in neighborhoods that were similar to them in terms of religious affiliation (eg Jewish adolescents raised in traditionally Jewish neighborhoods) had significantly lower levels of depressed affect than adolescents raised in religiously dissimilar neighborhoods. Similarly, Williams and $\mathrm{Hunt}^{35}$ found that Muslims living in Scotland experience nearly four times the likelihood of depressive symptoms as do non-Muslims living in Scotland. Whilst approximately $50 \%$ of the elevated risk could be explained as a function of differences in the social and psychological conditions between Muslims and non-Muslims (eg greater stress, lower standard of living, and lack of social support), even 
after controlling for such factors Muslims still had twice the odds of experiencing depressive symptoms as non-Muslims. Similar findings are reported for Ashkenazi Jews in various Israeli neighborhoods. ${ }^{36}$

Differences in religious involvement Another possible explanation for the observed differences in rates of depressive symptoms of various religious affiliations is that differences in the religious practices among these groups are responsible for the differences between religious groups. After all, nonreligious people are not simply 'not Jewish, Protestant, or Catholic'; they do not possess many religious attitudes, beliefs, and behaviors that are held by many religious people. Could it be that these differences in religious involvement explain the effects of religious affiliation on depression? It is to an intensive look at how such measures of beliefs and behavior predict depression and depressive symptoms that we now turn.

\section{Religious involvement and depression}

The number of studies that have examined the crosssectional association of at least some measure of religious involvement with some measure of depression is likely to be quite large. We have retrieved over 50 published studies that have examined the religion-depression association in some fashion. In general, it would be safe to conclude that these studies find measures of religiousness to be associated with measures of depression. However, the results across studies are not as consistent as one would like.

Aside from the most likely methodological explanation for lack of consistency in results - sampling error, ${ }^{38}$ perhaps the second most plausible explanation for lack of consistency in results is that the religiousness-depression relationship changes as a function of how religiousness is operationalized. In the section that follows, we attempt to find consistency in the religiousness-depression literature by examining results obtained when measuring specific aspects of religious involvement.

\section{Measures of general religious involvement}

Many cross-sectional studies have examined the association of multi-item measures of religious beliefs and behavior with measures of depressive symptoms. We refer to these measures as measures of 'general religious involvement', because they tend to combine indicators of public religious involvement (eg frequency of church attendance), private religious involvement (eg measures of the frequency of private prayer), and religious salience and motiva- tion (eg self-rated importance of one's faith) in a single index. Such measures tend to be quite reliable, since the measurement errors associated with each individual item tend to cancel each other out when the items are aggregated. ${ }^{39}$

Perhaps due to the measurement stability that is obtained when such multi-item measures are used, we see that they are uniformly and negatively correlated with measures of depressive symptoms and affect. ${ }^{32,40-49}$ The zero-order correlations between such measures and measures of depression appear to be in the range of $r=-0.07$ to -0.40 , with a central tendency in the neighborhood of $r=-0.20$.

When a variety of potential causes of spurious associations are controlled statistically, the associations between general measures of religious involvement and depression are adjusted downward dramatically, although not completely. For example, after controlling for age, marital status, geography, race, obesity, religious salience, and strength and comfort that people derived from their religion, Ferraro ${ }^{45}$ found that scores on a three-item measure of general religiousness were still negatively associated with depressive symptoms, but at a low magnitude $(\beta=-0.08)$. Other studies find that when other measures of religious involvement are controlled simultaneously (eg measures of religious affiliation and public religious involvement), the association of general religiousness with depression typically falls to trivial levels. ${ }^{32,44}$

There is an important lesson to be learned here. Allowing various measures of religiousness (which share a large amount of common variance) to 'fight' for common variance in a measure of depression is not the most theoretically sophisticated way to illuminate the association of religious involvement and depression. Such purely empirical approaches do not yield fundamental insights into the various pathways through which religious involvement might obtain its associations with measures of depression. Rather, they capitalize on chance and non-substantive differences in measurement reliability. If researchers truly want to determine whether several measures of religious involvement are differentially associated with depression, they should first confirm that the measures that they intend to pit against one another are indeed factorially distinct. If they are (and the researchers still insist on using them as simultaneous predictors of depression), then their covariances with each other and other variables of interest should be corrected for attenuation due to measurement unreliability prior to examining their unique contributions to the prediction of depression. ${ }^{39}$ Only then will the research on depression and religion yield a hard core of findings upon 
which a sophisticated theoretical understanding of the religion-depression relationship can be built.

\section{Organizational religious involvement}

Another common way to measure religiousness has been to assess people's involvement in public religious activities. By far the most common measures used to assess the relationship of religious involvement and depression have been single-item measures of attendance at religious services, membership in religious organizations, or short scales that combine two or more single-item measures of organizational religious involvement. Such measures are convenient to include in large survey databases; however, they are likely to contain remarkably little true score variance. ${ }^{39}$ Also, such measures are problematic because they might not accurately assess the religiousness of highly religious people who are not able to be involved in their religious congregations because of physical health limitations. ${ }^{50}$

Despite the psychometric limitations inherent in such measures of religious involvement, most studies that have assessed the relationship between organizational religious involvement and depression have found a small negative association. Of 29 studies that examined the cross-sectional association of a measure of organizational religious involvement (usually single-item measures assessing frequency of church attendance), 24 of them ${ }^{14,17,21,23-25,30,32,37,51-65}$ find people involved in a religious organization to have lower levels of depressive symptoms. They al so are less likely to be diagnosed with depressive disorders or score in the clinical range on dichotomized measures of depression. ${ }^{14,51,53,57,64}$ The balance of the 29 studies found associations between organizational religious involvement and depression so small as to be nearly zero. ${ }^{7,26,66-68}$

After stringent control of demographic, psychosocial, and health-related variables, the association between organizational religious involvement and depression drops substantially, usually yielding standardized regression coefficients in the range of $\beta=0.10,24,25,51,54,55,60,63,64,67$ al though estimates have extended as high as $\beta=-0.18^{58}$ Well-controlled multivariate studies using depressive diagnoses as the dependent variable suggest that lack of organizational religious involvement leads to a $20-60 \%$ increase in the odds of experiencing a major depressive episode. ${ }^{51,63}$ The largest decreases in the magnitude of the organizational religious involvementdepression relationship appear to occur when measures of social support, health status, and functional disability are added into multivariate equations, and it is possible that the unique association of religious involvement and depression is larger for women rather than for men. ${ }^{17}$

The longitudinal research on the effects of organizational religious involvement on depression presents a somewhat mixed picture. Much of the available longitudinal data suggests that the extent of one's organizational religious involvement at baseline does not strongly predict later depression when reasonable care is exerted to rule out potential demographic, psychosocial, or biomedical explanations. ${ }^{14,17,59,69}$ There are exceptions, however. ${ }^{37,70}$ Indeed, the best prospective study on the topic ${ }^{37}$ suggests that organizational religious involvement might be differentially related to later depressive symptoms as a function of one's religious affiliation. Using 7-year follow-up data from a random sample of 8866 American adults, Musick and Strulowitz ${ }^{37}$ estimated the prospective associations of attendance at formal religious activities and involvement in informal religious groups on two scales, measuring (a) the somatic retardation symptoms of depression $(\alpha=0.87)$, and (b) depressed affect $(\alpha=0.87)$. They assessed religious involvement with a two-item measure of involvement in two organized religious social events: (a) attendance at religious services and (b) church or synagogue-related social events. These two items were conceptually related and yielded an internal consistency estimate of $\alpha=0.59$. A second measure of organizational religious involvement assessed how often respondents participated in other religious groups.

Zero-order correlations of the depression variables and organizational religious involvement variables at baseline were small ( -0.04 to -0.06 ; although these estimates would in the -0.06 to -0.08 range if adjusted for attenuation due to unreliability in the dependent variables). Despite the small magnitude of these cross-sectional correlations, the longitudinal effects appeared to be considerable. When simultaneously controlling for sociodemographic variables and baseline levels of (a) somatic-retarded depressive symptoms, (b) physical health, and (c) several measures of social support, involvement in formal religious activities was negatively associated with somatic-retarded depressive symptoms at the 7-year follow up for most groups of Christians. Similar findings were found when depressed affect was used as a criterion variable. Among Jews ( $n=192)$, however, formal religious involvement at baseline had a positive net association with somatic-retarded depressive symptoms and with depressed affect at the 7-year follow-up. In contrast, participation in informal church groups was associated with lower levels of depressive symptoms for Jews on both measures of depression, whereas informal participation in church groups was associated with higher levels of depressive symptoms among Christians. 
Summary The data on organizational religious involvement and depression supports two conclusions. First, it seems clear that depression is indeed less prevalent among people who are involved in public religious activities. Second, for Americans and Europeans of Christian denominations, the best Iongitudinal research indicates that formal organizational religious involvement is related to a lower risk of depression over time; the converse is true for American Jews. Conversely, informal religious involvement appears to be associated prospectively with less depression for Jews, but with more depression for Christians. These differences could result from the different psychosocial resources provided by the two respective kinds of organizational activities for Christians and Jews in modern culture. ${ }^{37}$ Thus, although organizational religious activity does, in general, appear to deter depression, by no means does it do so in a 'one size fits all' fashion.

\section{Frequency of prayer and private religious activity}

Various studies have investigated the association of private religious activities such as private prayer, reading of scripture, and watching religious broadcasting with measures of depressive symptoms. Typically, such measures have been single-item indicators, ${ }^{24-26,53,58,63,67,71}$ al though some researchers have employed multi-item measures whose reliability can be estimated. ${ }^{17,54,55,57,61,64}$

By far, most studies suggest that private religious activity maintains a tenuous relationship with depression. Most studies find both the zero-order and multivariate associations to be small, regardless of whether private religious activity is measured with single-item or multi-item measures. Of course, there are exceptions to this general trend, with some studies finding evidence of small inverse associations of private religious involvement with depressive symptoms. ${ }^{55,61,67}$

Just as the cross-sectional evidence weighs against the hypothesis that private religious activities deter depression, the available longitudinal evidence al so does not bode well for this hypothesis. Koenig, George, and Peterson ${ }^{69}$ found that after controlling for 30 other variables, including heal th-rel ated variables, socio-economic measures, and intrinsic religious motivation, frequency of private religious activity was not significantly related to speed of remission of depression among 87 older adults who were hospitalized for medical illness. Idler and Kasl ${ }^{17}$ al so failed to find any longitudinal association of private religious involvement with scores on the CES-D scale at a 3-year follow-up after controlling for potential confounds.
Religious salience and motivation

Following Allport, ${ }^{72}$ social scientists typically distinguish between extrinsic religious motivation (a strictly utilitarian motivation for being religious) and intrinsic religious motivation (which regards religion as valuable in and of itself). Intrinsic religious motivation is typically associated with multi-item scales, such as those by Allport and Ross, ${ }^{73}$ Hoge, ${ }^{74}$ and Feagin. ${ }^{75}$ Several studies have al so used singleitem measures to assess people's impressions of their own degree of religiousness and the importance of religion to their identity. ${ }^{15,21,45,58,66}$ In general, these studies have found that such single item measures have rather small zero-order associations with measures of depressive symptoms (ie on the order of $r=0.00$ to 0.05 ). These weak relationships are not terribly surprising, since such single-item measures are likely to contain low amounts of reliable variance. $^{39}$

There are, of course, exceptions to this trend some studies using single-item measures of religious salience do find such measures inversely related to depression. ${ }^{15,26}$ Ross $^{15}$ found, for example, that a single-item measure of strength of religious belief was associated, after controlling for potential sociodemographic confounds and other religious measures, with reduced depressive symptoms in a sample of Illinois residents $(\beta=-0.12)$. However, such findings are exceptions when using single-item measures of religious salience. Measures of religious salience that aggregate multiple items produce zeroorder correlations with depression that are considerably higher. ${ }^{76}$ When we rely on studies that have used multi-item measures of intrinsic and extrinsic religious motivation, however, a different pattern emerges. Across several studies using the Allport-Ross, Hoge, and Feagin measures of intrinsic and extrinsic religious motivation, multi-item measures of extrinsic religious motivation have tended to be positively associated with self-report measures of depressive symptoms. The correlations of extrinsicness and depressive symptoms have typically been in the range of 0.03 to 0.25 , with a central tendency that appears to center around 0.15 or so. ${ }^{22,62,77-82}$ Thus, it would appear that people who are motivated to be religious because of the benefits that religion brings (eg comfort, security, affirmation of one's lifestyle) are actually disposed to slightly higher levels of depressive symptoms.

In contrast, multi-item measures of intrinsic religious motivation have tended to be negatively correlated with self-report measures of depressive symptoms. These correlations have typically been in the range of -0.05 to -0.36 , with a central tendency that appears to be centered around $-0.20 .^{22,25,30,62,65,71,77,78,81-84}$ Thus, it appears that 
people who are motivated to be religious by virtue of their conviction that being religious is worthwhile in and of itself are predisposed to slightly lower levels of depressive symptoms. Also, medically ill adults with high degrees of intrinsic religiousness are slightly less likely to be diagnosed with major depression. ${ }^{57}$ Further, it appears that people who are classified as intrinsically religious (based on established cut-off scores) have significantly lower scores on measures of depressive symptoms than people who are classified as extrinsically religious, ${ }^{77}$ and are only approximately $55 \%$ as likely as extrinsically religious people to receive a diagnosis of major depression, ${ }^{63}$ (even though the odds ratio becomes nearly 1.0 when health, income, education, and marital well-being are controlled).

Longitudinal research on religious salience, motivation, and depression is limited. One relevant longitudinal study ${ }^{22}$ suggests that intrinsic religiousness may indeed predict later depressive symptoms, even after controlling for baseline depressive symptoms (although this intrinsicness-depression effect was not replicated in a second sample). A more comprehensive study with a one-year follow-up ${ }^{85}$ found that people who indicated that 'a strong religious faith' was among the three most important things in life had only $38 \%$ of the odds of becoming depressed in comparison with those who did not ascribe such importance to their religious faith. Among those who were depressed at baseline, $(n=48)$ people who indicated that having a strong religious faith was among the most important things in life had only $17 \%$ of the odds of remaining depressed at the one-year follow-up as those individuals who did not ascribe such importance to their religious faith. Similarly, Koenig et $\mathrm{al}^{69}$ found that among 87 depressed older adults who were hospitalized for medical illness, scores on a ten-item measure of intrinsic religious motivation predicted length of time until patients were no longer depressed. Even after controlling for over 30 sociodemographic, medical, and psychosocial variables (including single-item measures of church attendance and private religious activities), a 10-point increase on the intrinsic religious motivation measure (approximately one standard deviation) was associated with $70 \%$ increase in speed of remission.

Summary The available data on religious salience, religious motivation, and depression lead to several conclusions. First, extrinsic religious motivation that is, being involved in religion for its potential to confer temporal benefits upon the individual - is associated with greater risk of depressive disorder and higher degrees of depressive symptomatology. Second, intrinsic religious motivation (as measured with single-item measures of religious salience, or with multi-item measures) tends to be negatively related to depressive symptoms. Third, in studies that examine whether early levels of intrinsic religious motivation predict longitudinal change in depressive symptoms after controlling for potential confounding variables, the hypothesis that intrinsic religious motivation actually helps to prevent depression fares well. However, large-scale replications of these longitudinal findings are sorely needed.

\section{Religious beliefs}

Do religious beliefs per se have any causal association with depression? This question is difficult to answer based on the existing research because so little of it exists, and what little that does exist is cross-sectional in nature. Hallstrom and Persson, ${ }^{53}$ Koenig, ${ }^{30}$ and Shafer $^{26}$ all found that single-item measures of belief in God (or in a personal God) and belief that Jesus was God's divine son were associated with lower levels of depressive symptoms (and in the case of Hallstrom and Persson, ${ }^{53}$ lower rates of depressive disorder). However, Mosher and Handal ${ }^{61}$ failed to find such an association of belief in God and depression.

Other specific religious beliefs fare poorly as predictors of depression. Mosher and Handal, ${ }^{61}$ Musick and Strulowitz, ${ }^{37}$ and Schafer ${ }^{26}$ found that conservative beliefs about the Bible, belief in Heaven and Hell, and belief in life after death were virtually uncorrelated with measures of depressive symptoms. In addition, using a factor score that was represented best by four items assessing conservative religious belief (eg belief in God, belief that God rewards and punishes, and literal belief in the Bible), Kendler, Gardner, Prescott ${ }^{46}$ found that conservative religious belief bore almost zero relationship $(\beta=0.02)$ with depressive diagnoses in a sample of 1800 female twins sampled from the state of Virginia.

\section{Conclusions}

This review of the existing research on religion and depression supports a few conclusions that should be of import for researchers examining religion from the perspective of psychiatric epidemiology.

\section{Substantive conclusions}

First, the data on religious affiliation and depression suggests that two religious groups - Jews and people who are not affiliated with a religion - are at an 
elevated risk of depression and depressive symptoms. These particular findings appear to be quite robust and well replicated across many data sets. Whilst such effects could indeed be causal, it appears most likely that these apparent effects are (at least in the case of Jews) a result of trade-offs in how latent predispositions for psychopathology are expressed in certain religious cultures. ${ }^{7}$

Second, it appears that some measures of religious involvement are indeed associated with depression. People who are involved frequently in organized religion and who highly value their religious faith for intrinsic reasons are at substantially reduced risk of depressive disorder and depressive symptoms. They also appear to recover more quickly from depressive episodes and are less likely to become depressed over time. Conversely, people who are involved in religion for reasons of self-interest are at a decidedly higher risk for depressive symptoms. Whilst the longitudinal data at present is limited, it does give tremendous incentive for further inquiry into the possibly causal nature of the religious involvement-depression relationship.

Third, there appear to be certain manifestations of religious involvement - particularly private religious activities and religious beliefs - that bear no lawful association with measures of depression and depressive symptoms. The fact that some measures are reliably associated with depression, whilst others are not, should be particularly useful as researchers attempt to build more sophisticated theories to explain the religion-depression relationship. Such findings might also be useful in the future in designing strategies for epidemiological surveillance, depression screening, and primary prevention.

\section{A methodological note}

We close with a methodological note. Future research on religion and psychiatric epidemiology must deal with the fact that self-report measures of religious involvement are typically correlated moderately with one another. For example, a measure of (a) the frequency of one's church attendance, (b) selfrated religiousness, and (c) frequency of private prayer are likely to be correlated on the order of 0.30 or better. Musick and Strulowitz ${ }^{37}$ for example, found frequency of formal church attendance and informal organizational religious involvement to be correlated at $r=0.70$, and they were correlated with conservative beliefs about the Bible at $r=0.38$ and 0.32 , respectively. These associations would not be considered trivial by psychometricians; they suggest that various self-report measures of religious involvement could very well be assessing the same underlying construct(s) over and over again.
Prior to conducting statistical analyses on data from epidemiological investigations of religion, we recommend that researchers examine the construct validity of the religious measures beforehand to determine that they are indeed assessing distinct constructs. Even better, researchers might use measures of religious involvement whose psychometric properties are well known and whose construct validity are well established. Many measures of religious involvement with well-known psychometric properties are available, and researchers who wish to take the measurement of religion in psychiatric epidemiology seriously should become acquainted with these measures. ${ }^{86}$ Steps taken to improve the reliability (and construct validity) of measures of religion used in epidemiological investigations in particular (and in social scientific research in general) will help the field to build a body of highly replicable findings about the nature of the religion-depression relationship in particular, and the role of religion in psychiatric epidemiology in general.

\section{Acknowledgements}

Portions of this article were presented at the conference on Religion, Values, and Health: Unraveling the Role of Genes and Environment at the Center for Theology and the Natural Sciences, Berkeley, CA, on 12-15 November 1998.

\section{References}

1 American Psychiatric Association. Diagnostic and Statistical Manual of Mental Disorders, 4th edn. American Psychiatric Association: Washington, DC, 1994.

2 Pincus HA, Tanelian TL, Marcus SC, Olfson M, Zarin DA, Thompson J, Magno Zito J. Prescribing trends in psychotropic medications: Primary care, psychiatry, and other medical specialties. JAMA 1998; 7: 526-531.

3 Koenig HG, George LK. Depression and physical health outcomes in depressed medically ill hospitalized older adults. Am J Geri Psychiatry 1998; 6: 230-247.

4 Kraeplin E. Studierende und Ärzte. In: Psychiatrie, ein Lehrbuch für Studierende und Ärtze. Verlag Von Johann Ambrosius Barth: Leipzig, 1899.

5 Sanua VD. Mental illness and other forms of psychiatric deviance among contemporary Jewry. Transcult Psychiatr Res Rev 1992; 29: 197-233.

6 Kosmin BA, Lachman SP. One Nation Under God. Harmony: New York, 1993.

7 Levav I, Kohn R, Golding JM, Weissman MM. Vulnerability of Jews to affective disorders. Am J Psychiatry 1997; 154: 941-947.

8 Bart P. Depression in middle-aged women: Some sociocultural factors. Unpublished doctoral dissertation, University of California, Los Angeles, 1968. 
9 Cooklin RS, Ravindran A, Carney MWP. The patterns of mental disorder in Jewish and non-Jewish admissions to a district general hospital psychiatric unit. Is manic-depressive illness a typically Jewish disorder? Psych Med 1983; 13: 209-212.

10 Fernando S.M. Aspects of depression in a Jewish minority group. Psychiatrica Clinica 1978; 11: 22-33.

11 Figelman MA. A comparison of affective and paranoid disorders in Negroes and Jews. Int J Soc Psychiatry 1968; 14: 277-281.

12 Flics DH, Herron WG. Activity-withdrawal, diagnosis, and demographics as predictors of premorbid adjustment. J Clin Psychol 1991; 47: 189-198.

13 Malzberg B. Mental disease among Jews in New York State, 1960-1961. Acta Psychiatrica Scandinavica 1973; 49: 479-518.

14 Kennedy GJ, Kelman HR, Thomas C, Chen J. The relation of religious preference and practice to depressive symptoms among 1,855 older adults. J Gerontology: Psychological Sciences 1996; 51B: P301-P308.

15 Ross CE. Religion and psychological distress. J Sci Study Rel 1990; 29: 236-245.

16 Yeung PP, Greenwald S. Jewish Americans and mental health: Results of the NIMH Epidemiologic Catchment Area study. Soc Psychiatry Psychiatric Epi 1992; 27: 292-297.

17 Idler EL, Kasl SV. Religion, disability, depression, and the timing of death. Am J Sociology 1992; 97: 1052-1079.

18 Kennedy GJ. Religion and depression. In: Koenig HG (ed.). Handbook of Religion and Mental Health. Academic Press: San Diego, 1998, pp 129-145.

19 Glicksman A. The New Jewish Elderly. American Jewish Committee: New York, 1991.

20 Miller L, Warner V, Wickramaratne P, Weissman M. Religiosity and depression: Ten-year follow-up of depressed mothers and offspring. J Am Acad Child Adol Psychiatry 1997; 36: $1416-1425$

21 Sorenson AM, Grindstaff CF, Turner RJ. Religious involvement among unmarried adolescent mothers: A source of emotional support? Sociology of Religion 1995; 56: 71-81.

22 Park C, Cohen LH, Herb L. Intrinsic religiousness and religious coping as life stress moderators for Catholics versus Protestants. J Pers Soc Psych 1990; 59: 562-574.

23 Hertsgaard D, Light H. Anxiety, depression, and hostility in rural women. Psychological Reports 1984; 55: 673-674.

24 Sherkat DE, Reed MD. The effects of religion and social support on self-esteem and depression among the suddenly bereaved. Social Indicators Research 1992; 26: 259-275.

25 Commerford MC, Reznikoff M. Relationship of religion and perceived social support to self-esteem and depression in nursing home residents. J Psychology 1996; 130: 35-50

26 Schafer WE. Religiosity, spirituality, and personal distress among college students. J College Student Development 1997; 38: 633-644.

27 Jones-Webb RJ, Snowden LR. Symptoms of depression among blacks and whites. Am J Public Health 1993; 83: 240-244.

28 Meador KG, Koenig HG, Hughes DC, Blazer DG, Turnbull J, George LK. Religious affiliation and major depression. Hosp Comm Psychiatry 1992; 43: 1204-1208.

29 Koenig HG, George LK, Meador KG, Blazer DG, Dyck PB Religious affiliation and psychiatric disorder among Protestant baby boomers. Hosp Comm Psychiatry 1994; 45: 586-596.

30 Koenig HG. Religion and older men in prison. Int J Geriatric Psychiatry 1995; 10: 219-230.

31 Koenig HG, Cohen HJ, Blazer DG, Pieper C, Meador KG, Shelp F, Goli V, DiPasquale B. Religious coping and depression among elderly, hospitalized medically ill men. Am J Psychiatry 1992; 149: 1693-1700.

32 Brown DR, Gary LE. Religious involvement and health status among African-American males. J Nat Med Assoc 1994; 86: 825-831.
33 Ellison CG. Race, religious involvement, and depressive symptomatology in a southeastern US community. Soc Sci Med 1995; 40: 1561-1572.

34 Rosenberg $\mathrm{M}$. The dissonant religious context and emotional disturbance. Am J Sociology 1962; 68: 1-10.

35 Williams R, Hunt K. Psychological distress among British South Asians: The contribution of stressful situations and subcultural differences in the West of Scotland Twenty-07 Study. Psych Med 1997; 27: 1173-1181.

36 Rahav M, Goodman AB, Popper M, Lin SP. Distribution of treated mental illness in the neighborhoods of Jerusalem. Am JPsychiatry 1986; 143: 1249-1254.

37 Musick MA, Strulowitz S. Public religious activity and depressive symptomatology: A comparison of religious groups in the United States. (Submitted Soc Sci Med).

38 Hunter JE, Schmidt FL. Methods of Meta-Analysis. Sage: Newbury Park, CA, 1990.

39 Schmidt FL, Hunter J. Measurement error in psychological research: Lessons from 26 research scenarios. Psych Methods 1996; 1: 199-223.

40 Bienenfeld D, Koenig HG, Larson DB, Sherrill KA. Psychosocial predictors of mental health in a population of elderly women: Test of an explanatory model. Am J Geriatric Psychiatry 1997; 5 : 43-53.

41 Brown DR, Ndbuisi SC, Gary LE. Religiosity and psychological distress among blacks. J Religion and Health 1990; 29: 55-68.

42 Brown DR, Gary LE, Greene AD, Milburn NG. Patterns of social affiliation as predictors of depressive symptoms among urban blacks. J Health and Social Behavior 1992; 33: 242-253.

43 Brown DR, Gary LE. Stressful life events, social support networks, and the physical and mental health of urban black adults. JHuman Stress 1987; Winter: 165-174.

44 Fehring RJ, Brennan PF, Keller ML. Psychological and spiritual well-being in college students. Research in Nursing and Health 1987; 10: 391-398.

45 Ferraro K. Firm believers? Religion, body weight, and wellbeing. Rev Rel Res 1998; 39: 224-244.

46 Kendler KS, Gardner CO, Prescott CA. Religion, psychopathology, and substance use and abuse: A multimeasure, geneticepidemiologic study. Am J Psychiatry 1997; 154: 322-329.

47 Morse CK, Wisocki PA. Importance of religiosity in elderly adjustment. Religion and Aging 1987; 4: 15-26.

48 Pressman P, Lyons JS, Larson DB, Strain J. Religious belief, depression, and ambulation status in elderly women with broken hips. Am J Psychiatry 1990; 147: 758-760.

49 Strayhorn $\mathrm{M}$, Weidman CS, Larson DB. A measure of religiousness, and its relation to parent and child mental health variables. J Community Psychology 1990; 18: 34-43.

50 Idler EL, Kasl SV. Religion among disabled and nondisabled persons II: Attendance at religious services as a predictor of the course of disability. J Gerontology B: Psychological and Social Sciences 1997; 52: S306-S316.

51 Braam AW, Beekman ATF, van Tilburg TG, Deeg DJ, van Tilburg W. Religious involvement and depression in older Dutch citizens. Soc Psychiatry Psychiatric Epi 1997; 32: 284-291.

52 Brown GW, Prudo R. Psychiatric disorder in a rural and an urban population: 1. Aetiology of depression. Psych Med 1981; 11: 581-599.

53 Hallstrom T, Persson G. The relationship of social setting to major depression. Acta Psychiatrica Scandinavica 1984; 70: 327-336.

54 Husaini BA, Blasi AJ, Miller O. Does public and private religiosity have a moderating effect on depression? A biracial study of elders in the American south. Int JAging and Human Development (in press). 
55 Idler EL. Religious involvement and the heal th of the elderly: Some hypotheses and an initial test. Social Forces 1987; 66: 226-238.

56 Thearle MJ, Vance JC, Najman JM. Church attendance, religious affiliation, and parental responses to sudden infant death, neonatal death and stillbirth. Omega 1995; 31: 51-58.

57 Koenig HG, Moberg DO, Kvale N. Religious activities and attitudes of older adults in a geriatric assessment clinic. JAm Geriatrics Society 1988; 36: 362-374.

58 Koenig HG, Pargament KI, Nielsen J. Religious coping and health status in medically ill hospitalized older adults. J Nervous and Mental Disease 1998; 186: 513-521.

$59 \mathrm{Maton} \mathrm{KI}$. The stress-buffering role of spiritual support: Crosssectional and prospective investigations. JSci Study Rel 1989; 28: $310-323$.

$60 \mathrm{Mclntosh}$ BR, Danigelis NL. Race, gender, and the rel evance of productive activity for elders' affect. J Gerontology: Social Sciences 1995; 50B: S229-S239.

61 Mosher $\mathrm{P}$, Handal PJ. The relationship between religion and psychological distress in adol escents. JPsychology and Theology $1997 ; 25: 449-457$.

62 Nelson PB. Ethnic differences in intrinsic/extrinsic religious orientation and depression in the elderly. Archives of Psychiatric Nursing 1989; 3: 199-204

63 Spendlove DC, West DW, Stanish WM. Risk factors and the prevalence of depression in Mormon women. Soc Sci Med 1984; 18: 491-495.

64 Strawbridge WJ, Shema SJ, Cohen RD, Roberts RE, Kaplan GA. Religiosity buffers effects of some stressors on depression but exacerbates others. J Gerontology: Social Sciences 1998; 59B: S118-S126.

65 Wright LS, Frost CJ, Wisecarver SJ. Church attendance, meaningfulness of religion, and depressive symptomatology among adolescents. J Youth and Adolescence 1993; 22: 559-568.

66 Levin JS, Markides KS. Religion and health in MexicanAmericans. J Rel Health 1985; 24: 60-67.

67 Musick MA, Williams DR, Jackson JS. Race-related stress, religion, and mental health among African-American adults. Seventh International Conference on Social Stress Research. Budapest, Hungary, 1998

68 Siegel JM, Kuykendall DH. Loss, widowhood, and psychological distress among the elderly. J Consult Clin Psychology 1990; 58: 519-524.

69 Koenig HG, George LK, Peterson BL. Religiosity and remission of depression in medically ill older patients. Am JPsychiatry 1998; 155: 536-542.

70 Musick MA, Koenig HG, Hays JC, Cohen HJ. Religious activity and depression among community-dwelling elderly persons with cancer: The moderating effect of race. J Gerontology (in press).
71 Pargament KI, Ensing DS, Falgout K, Olsen H, Reilly B, Van Haitsma K, Warren R. God help me: I: Religious coping efforts as predictors of the outcomes to significant life events. Am J Community Psychology 1990; 18: 793-824.

72 Allport GW. The Individual and his Religion. Macmillan: New York, 1950.

73 Allport GW, Ross M. Personal religious orientation and prejudice. JPers Soc Psychology 1967; 5: 432-443.

74 Hoge DR. A validated intrinsic religious motivation scale. JSci Study Rel 1972; 11: 369-376.

75 Feagin $\mathbf{R}$. Prejudice and religious types: A focused study of Southern fundamentalists. J Sci Study Rel 1964; 4: 3-13.

76 Plante TG, Boccaccini MT. The Santa Clara Strength of Religious Faith Questionnaire. Pastoral Psychology 1997; 45: 375-387.

77 Genia V, Shaw DG. Religion, intrinsic-extrinsic orientation, and depression. J Sci Study Rel 1991; 32: 274-283.

78 Rigby RM, Ryan S, King K. Two types of religious internalization and their relations to religious orientations and mental health. J Pers Soc Psychology 1993; 65: 586-596.

79 Rosik $\mathrm{CH}$. The impact of religious orientation in conjugal bereavement among older adults. Int JAging Human Development 1989; 28: 251-260.

80 Rutledge J, Spilka B. Coping with intimacy: A problem for the single adult Mormon. Paper presented at the annual meeting of the American Psychological Association. Toronto, Ontario, August 1993.

81 Watson PJ, Morris RJ, Hood RW. Sin and self-functioning, Part 1: Grace, guilt, and self-consciousness. JPsychology Theology 1988; 16: 254-269.

82 Watson PJ, Morris RJ, Hood RW. Sin and self-functioning, Part 4: Depression, assertiveness, and religious commitments. J Psychology Theology 1989; 17: 44-58.

83 O'Connor BP, Vallerand RJ. Religious motivation in the elderly: A French-Canadian replication and an extension. $J$ Soc Psychology 1990; 130: 53-59.

84 Park CL, Cohen LH. Religious and nonreligious coping with the death of a friend. Cogn Therapy Research 1993; 17: 561-577.

85 Braam AW, Beekman ATF, Deeg DGH, Smit H, van Tilburg W. Religiosity as a protective of prognostic factor of depression in Iater life; results from a community study in The Netherlands. Acta Psychiatrica Scandinavica 1997; 96: 199-205.

86 Hill PC, Hood R. Measures of religiosity. Religious Education Press: Birmingham, AL (in press). 